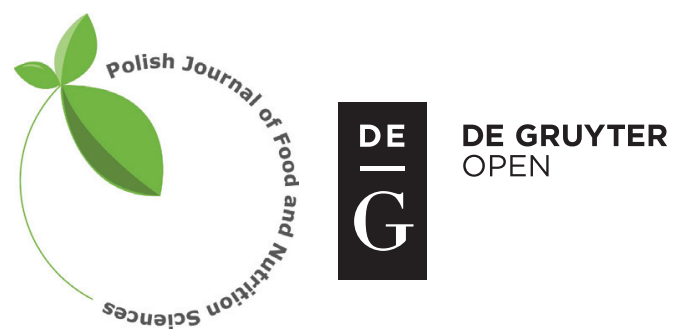

Pol. J. Food Nutr. Sci., 2018, Vol. 68, No. 1, pp. 33-43 DOI: $10.1515 /$ pjfns-2017-0011 http://journal.pan.olsztyn.pl

Original research article

Section: Food Technology

\title{
Production and Application of Lysozyme-Gum Arabic Conjugate in Mayonnaise as a Natural Preservative and Emulsifier
}

\author{
Marjan M. Hashemi ${ }^{*}$, Mahmoud Aminlari ${ }^{2,5}$, Mehdi M. Forouzan ${ }^{3}$, Esmaeel Moghimi ${ }^{4}$, \\ Maryam Tavana $^{5}$, Shahram Shekarforoush ${ }^{6}$, Mohammad Amin Mohammadifar ${ }^{7}$
}

\author{
'Department of Chemistry and Biochemistry, Brigham Young University, C100 BNSN, Provo, UT 84602, USA \\ 2Department of Food Science and Technology, School of Agriculture, Shiraz University, Shiraz 71345, Iran \\ ${ }^{3}$ Department of chemical engineering, Brigham Young University, Provo, UT 84602, USA \\ ${ }^{4}$ Department of Materials Science and Technology, University of Crete, 71110 Heraklion, Greece \\ ${ }^{5}$ Department of Biochemistry, School of Veterinary Medicine, Shiraz University, Shiraz 71345, Iran \\ ${ }^{6}$ Department of Food Hygiene, School of Veterinary Medicine, Shiraz University, Shiraz 71345, Iran \\ ${ }^{7}$ Department of Food Science and Technology, National Nutrition and Food Technology Research Institute, \\ Shahid Beheshti University of Medical Sciences, 7, West Arghavan St., Farahzadi Blvd., Tehran, Iran
}

Key words: lysozyme, gum Arabic, conjugate, functional properties, mayonnaise, rheology

Nowadays demand for food products made by natural sources is rising so fast. In this work Lysozyme (Lyz) was conjugated with gum Arabic (GA) in order to be applied in mayonnaise, at which the presence of both preservative and emulsifier is essential. Interestingly, the Lyz-GA conjugate exhibited improved functional properties and antibacterial activity. In order to approve the results of this study, the Lyz-GA conjugate was applied to mayonnaise as a natural preservative and emulsifier. Application of the Lzy-GA conjugate in mayonnaise expedited the death rate of both $S$. aureus and $E$. coli $K-12$. The observation proved that conjugations of Lyz with GA increased the spectrum of its application in food products with improved antibacterial activity. Surprisingly, investigation of emulsion stability and rheological properties confirmed the improved emulsification role of Lyz-GA conjugate with a higher elasticity in the mayonnaise. Mayonnaise including conjugates showed a linear rheological response and shear-thinning behavior. Sensory analysis of the mayonnaise with Lyz-GA conjugate was completely consistent with the commercial one. Taken together, our results suggest that conjugation of Lyz with GA made possible the application of a natural preservative and emulsifier in food and pharmaceutical industries, whereas Lyz alone does not have a broad-spectrum antibacterial activity or emulsifying properties.

\section{INTRODUCTION}

Food products with natural resources have interested both costumers and food producers. Mayonnaise, an oil-in-water emulsion and one of the most well-known sauces, is a product with a high demand by costumers who prefer to have a healthier product without chemical preservatives. Therefore, the chemical preservatives in mayonnaise have been mainly replaced with natural ones, such as organic acid and bacteriocins [Fialová et al., 2008]. Lysozyme (Lyz), E.C.3.2.17, $\mathrm{N}$-acetyl-muramic-hydrolase, is a bacteriolytic enzyme, which is generally found in nature. Recently, Lyz has received considerable attention as a natural preservative. When modified with fatty acids either hydrophobic peptides, or polysaccharides, Lyz can be changed to a potent bactericidal agent against Gram-negative bacteria like E. coli. However, because of its effect on the cell wall of the Gram-positive bacteria but

\footnotetext{
* Corresponding Author: Tel.: (801)473-6285; Fax: (801)422-0153;

E-mail: Marjan.mhashemi@byu.edu
}

not on the Gram-negatives, the industrial application of Lyz is limited [Aminlari et al., 2014; Benucci et al., 2016].

Proteins and polysaccharides are the main constituents of foods, and contribute to the rheological and functional characters of the food systems [Dickinson, 2003]. Polysaccharides are widely used for stabilization of food emulsions and foams. Gum Arabic (GA), an anionic arabinogalactan-protein polysaccharide, is a tree gum exudate and water soluble which is extensively used in food and pharmaceutical industries, due to its unique emulsification, film forming, and encapsulation properties [Phillips \& Williams, 2000]. The reaction between GA and some proteins, like $\beta$-lactoglobulin [Schmitt et al., 2005], casein [Flanagan \& Singh, 2006], and soy protein isolates [Mu et al., 2011] has recently been studied. High molecular weight emulsifiers, such as GA, dextran, and modified starch, are often used as ingredients to stabilize oil-in-water food emulsions [Mu et al., 2011].

As mentioned, Lyz is applied to food products as a natural preservative, also hydrocolloids, like GA, contribute an important part to the food industry. Thus, the implementation of conjugates, including both GA and Lyz, with improved functional 
and antimicrobial properties, provides the mayonnaise industry with a great opportunity. In fact, they can take advantage of the simultaneous effect of applying the Lyz-GA conjugates as a natural preservative and emulsifier, which plays a key role in producing a satisfactory product. Conjugation can be done through the Millard reaction without additional chemical coupling agents, which was found to be a safe and useful method to improve functional properties of proteins [Dickinson, 2003; Aminlari et al., 2005 ]. In this method, the reaction occurs between the $\varepsilon$-amino groups in protein and the reducing end carbonyl group of polysaccharide under controlled-dry heating [Miralles et al., 2007; Jiménez-Castaño et al., 2007].

This investigation was aimed at conjugating Lyz with GA through gaining optimized conditions, via different $\mathrm{pH}$, time of incubation and weight ratio of protein (Lyz) to polysaccharide (GA) through the Maillard reaction. Furthermore, the effect of the covalent bond of GA to Lyz on functional properties and antimicrobial activity against Staphylococcus aureus and Escherichia coli was studied. Finally, in an attempt to study the result in a food system, the produced Lyz-GA conjugate was applied to mayonnaise as a natural preservative and emulsifier, and texture characterization of mayonnaise, which is of paramount importance for consumers [Liu et al., 2007], was investigated through rheological experiments and sensory analysis.

\section{MATERIAL AND METHODS}

\section{Materials}

The materials used in this work were as follows: hen egg white Lyz (Mr 14600) was supplied by Inovatech, Inc (Abbotsford, BC, Canada). Protein molecular weight markers were provided by Fermentas (Molndal, Sweden). GA (Acacia), Micrococcus lysodeikticus cells, Xanthan gum, citric acid and all other chemicals were provided by Sigma (St. Louis, MO). Mayonnaise ingredients including sunflower oil, vinegar, mustard powder, pasteurized egg, sugar, and salt were all purchased from local stores.

\section{Lyz-GA conjugate preparation}

Lyz-GA conjugate was prepared at $\mathrm{pH} 7.0$ and 8.5 as described in our previous work [Hashemi et al., 2014]. Lyz and GA in a weight ratio of 1:1, 1:2 and 1:4 (200:800 mg) were dissolved in $10 \mathrm{~mL}$ of sodium phosphate buffer with a concentration of $0.1 \mathrm{~mol} / \mathrm{L}(\mathrm{pH} 7.0$ and 8.5$)$. The solution was incubated at room temperature for $1 \mathrm{~h}$ and then lyophilized at $-70^{\circ} \mathrm{C}$. The lyophilized products were incubated in sealed glass desiccators at $60^{\circ} \mathrm{C}$ under the relative humidity of $79 \%$ provided by saturated $\mathrm{KBr}$. To study kinetics of conjugation between Lyz and GA, samples were removed at particular time intervals, and employed for SDS-PAGE. A control sample without any GA was also prepared for each experiment.

\section{SDS-PAGE}

Slab SDS-PAGE was performed according to the discontinuous buffer system of Laemmli [1970].

\section{Fourier Transform Infrared Spectroscopy (FTIR)}

In an effort to study the structures of the samples, FTIR spectra of GA, Lyz, Lyz-GA conjugates were determined on a BRUCKER spectrophotometer (EQUINOX 55, Germany). Dry samples were grinded with $300 \mathrm{mg} \mathrm{KBr}$ and pressed into a pellet, thereby the structure of the proteins in the dry solid was not changed with this protocol. The average of 16 scans at $2 \mathrm{~cm}^{-1}$ resolution in the range of $4,500-500 \mathrm{~cm}^{-1}$ were taken.

\section{Determination of functional properties}

\section{Protein solubility}

In order to measure protein solubility the method suggested by Kotlar et al. [2013] was applied with some modification. Shortly, nitrogen content of the samples was determined using micro-Kjeldahl procedure (instead of Lowry) and was placed in the formula as follows:

\section{$\%$ Protein Solubility $=$ [nitrogen in the supernatant $/$ /total nitrogen in sample powder] $\times 100 \%$}

Different $\mathrm{pH}$ values including 3,5, 7, and 9 and different temperatures including 25,40 , and $60^{\circ} \mathrm{C}$ were studied to determine the highest protein solubility.

\section{Emulsifying activity (EA) and emulsion stability (ES)}

The emulsion activity and stability were measured using the method described by Song et al. [2002]. EA was determined by recording the absorbance of the emulsion prepared by corn oil and Lyz derivatives solution (in $0.1 \mathrm{~mol} / \mathrm{L}$ sodium phosphate, $\mathrm{pH} 7.4$ ) at $500 \mathrm{~nm}$ at zero time using a Shimadzu spectrophotometer. In addition, the ES was determined as the time required to obtain a $50 \%$ decrease in absorbance.

\section{Foaming capacity (FC) and stability (FS)}

Foaming properties were measured based upon the method described by Chevalier et al. [2001] with some modification. Briefly, a foamed solution including Lyz derivatives and distilled water was prepared using a homogenizer at $8000 \mathrm{rpm}$ for $5 \mathrm{~min}$. The difference in the volume of the protein dispersion followed by mixing was defined as the FC, whereas the percentage of foam remaining after 30 min was defined as FS.

\section{Heat stability evaluation}

The absorbance at $500 \mathrm{~nm}$ of un-conjugated and conjugated Lyz solutions $(7.5 \mathrm{mg}$ per $10 \mathrm{~mL}$ of $0.1 \mathrm{~mol} / \mathrm{L}$ sodium phosphate, $\mathrm{pH} 7.4$ ) held at $50^{\circ} \mathrm{C}$ to $95^{\circ} \mathrm{C}$ was measured to determine the heat stability. The temperature (started at $50^{\circ} \mathrm{C}$ ) was increased by $1^{\circ} \mathrm{C}$ per min and absorbance was recorded every 5 min [Aminlari et al., 2005].

\section{DPPH (Diphenyl picryl hydrazyl) radical scavenging activity}

According to the method described by Arabshahi-D et al. [2007], DPPH radicals were used to study the scavenging activity of the samples. The activity was calculated using the equation as follows:

$$
\begin{gathered}
\text { Radical scavenging activity }(\%)= \\
=\left[\left(\mathrm{Abs}_{\text {control }}-\mathrm{Abs}_{\text {sample }}\right) / \mathrm{Abs}_{\text {control }}\right] \times 100 \%
\end{gathered}
$$

The absorbance was measured at $517 \mathrm{~nm}$. 


\section{Antimicrobial activity}

The antimicrobial activity was studied by the microbial plate count, which was used in our previous work [Hashemi et al., 2014], to determine the antimicrobial activities of lyz derivatives against $E$. coli (as a representative Gram-negative bacteria) and $S$. aureus (as a representative Gram-positive bacteria).

\section{Mayonnaise production}

Mayonnaise was prepared as described by Leuschner \& Boughtflower [2001] with some modifications. The basic formulations included sunflower oil, vinegar, egg yolk, water, sugar, salt, mustard powder, citric acid, and xanthan gum.

The production process was as follows: all the ingredients except oil and vinegar were mixed for $1 \mathrm{~min}$. Subsequently sunflower oil was added drop by drop during continuous blending for $5 \mathrm{~min}$. Finally, after forming a texture, vinegar was added and mixed for $5 \mathrm{~min}$. The total time of mixing was around 15 min [Laca et al., 2010].

\section{Detection of antibacterial properties of mayonnaise containing Lyz-GA conjugate}

The antimicrobial properties of the following mayonnaise samples which are contaminated by $S$. aureus and $E$. coli were investigated using the method provided by Amiri et al. [2008]: (1) mayonnaise without conjugate (control); (2) mayonnaise containing $0.27 \mu \mathrm{mol} / \mathrm{L} \mathrm{Lyz}$ and GA (untreated); and mayonnaise containing $0.27 \mu \mathrm{mol} / \mathrm{L} \mathrm{Lyz-GA}$ conjugate.

\section{Mayonnaise emulsion stability}

The separated phase on top of the mayonnaise stored for 15 days at $20^{\circ} \mathrm{C}$ was weighed $\left(\mathrm{W}_{1}\right)$ on the third, fifth, eighth, tenth and fifteenth day, respectively. Likewise, $\mathrm{pH}$ measurement of uncontaminated samples was performed at the same time to evaluate if it was in the standard range (3.8-4.1) [Fialová et al., 2008].

The stability loss was calculated through the following equation, in which $\mathrm{W}_{0}$ is the total weight of the samples [Mandala et al., 2004]:

$$
\text { Emulsion stability loss }=\left(W_{1} / W_{0}\right) * 100
$$

\section{Rheological measurements of mayonnaise}

Rheological experiments were conducted on an AntonPaar MCR 301 with vane geometry (ST14-4V-35-SN16727; $\mathrm{d}=0 \mathrm{~mm})$. The temperature $(T)$ was set at $20^{\circ} \mathrm{C}$ using a standard Peltier plate. Dynamic frequency sweep (DFS) experiments were performed with strain amplitude of $1 \%$, which is well in the linear viscoelastic regime (see Figure 7). Dynamic strain sweep (DSS) measurements were done from strain amplitude of $0.1 \%$ to $1000 \%$ at the frequency $f=1 \mathrm{~Hz}$.

Flow curve measurements were conducted at shear rates ranging from $0.01 \mathrm{~s}^{-1}$ to $100 \mathrm{~s}^{-1}$. Herschel-Bulkley equation was used to model the flow curve results:

$$
\tau=\tau_{y}+\mathrm{k} \dot{\gamma}^{n}
$$

where: $\tau$ is shear stress, $\tau_{y}$ is yield stress, $k$ is consistency index, $\dot{\gamma}$ is shear rate, and $\mathrm{n}$ is flow index behavior.

\section{Sensory analysis}

Sensory evaluation was carried out on the mayonnaise samples by a panel consisting of 15 selected judges trained in 2-h sessions prior to evaluation in order to be familiar with attributes and scaling procedures of the mayonnaise samples. We evaluated appearance, color, odor, texture, taste, and overall acceptability as the sensory features on a five-point hedonic scale expressing 1 as the lowest and 5 as the highest. Evaluation was performed under laboratory conditions at about $24^{\circ} \mathrm{C}$. Water was used in order to cleanse the palate [Liu et al., 2007].

\section{Statistical analysis}

All data were recorded as means \pm standard deviation of triplicate measurements. Analyses of variance were performed by ANOVA and T-test procedure of SPSS 16.0 and significant differences between the means were determined with the Duncan's New Multiple Range Test $(\mathrm{p}<0.05)$.

\section{RESULTS AND DISCUSSION}

\section{Formation of Lyz-GA conjugate}

Figure $1 \mathrm{a}$ and $\mathrm{b}$ shows the effect of $\mathrm{pH}$ and the incubation time on the course of conjugation. At both $\mathrm{pH} 7.0$ and 8.5, the degree of conjugation increased with the incubation time, and higher conjugation occurred at $\mathrm{pH} 8.5$ (Figure 1b), suggesting more covalent attachment of GA to $\mathrm{Lyz}$ at $\mathrm{pH} 8.5$. Generally, the higher $\mathrm{pH}$ results in more product with greater
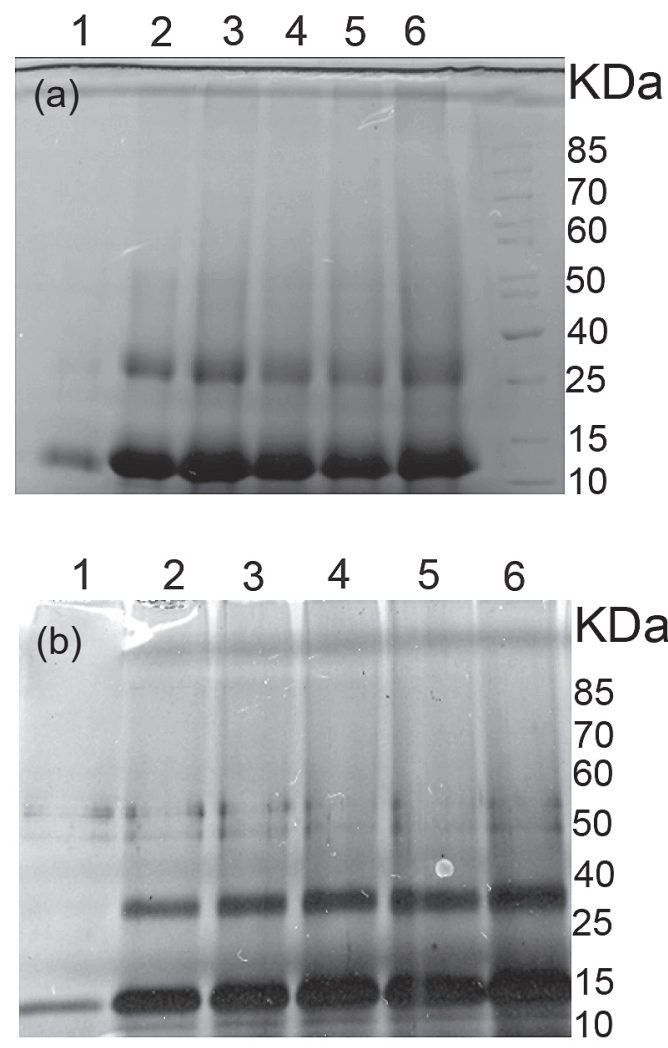

FIGURE 1. SDS-PAGE pattern showing the time course of Lyz-GA conjugation at (a) $\mathrm{pH} \mathrm{7,} \mathrm{(b)} \mathrm{pH} 8.5$ at $60^{\circ} \mathrm{C}$ and $79 \% \mathrm{RH}$. (15\% acrylamide gel, $20 \mu$ p protein per well). Lane 1, 0 day; lane 2, 2 days; lane 3, 4 days; lane 4,6 days; lane 5, 8 days; lane 6,10 days. 


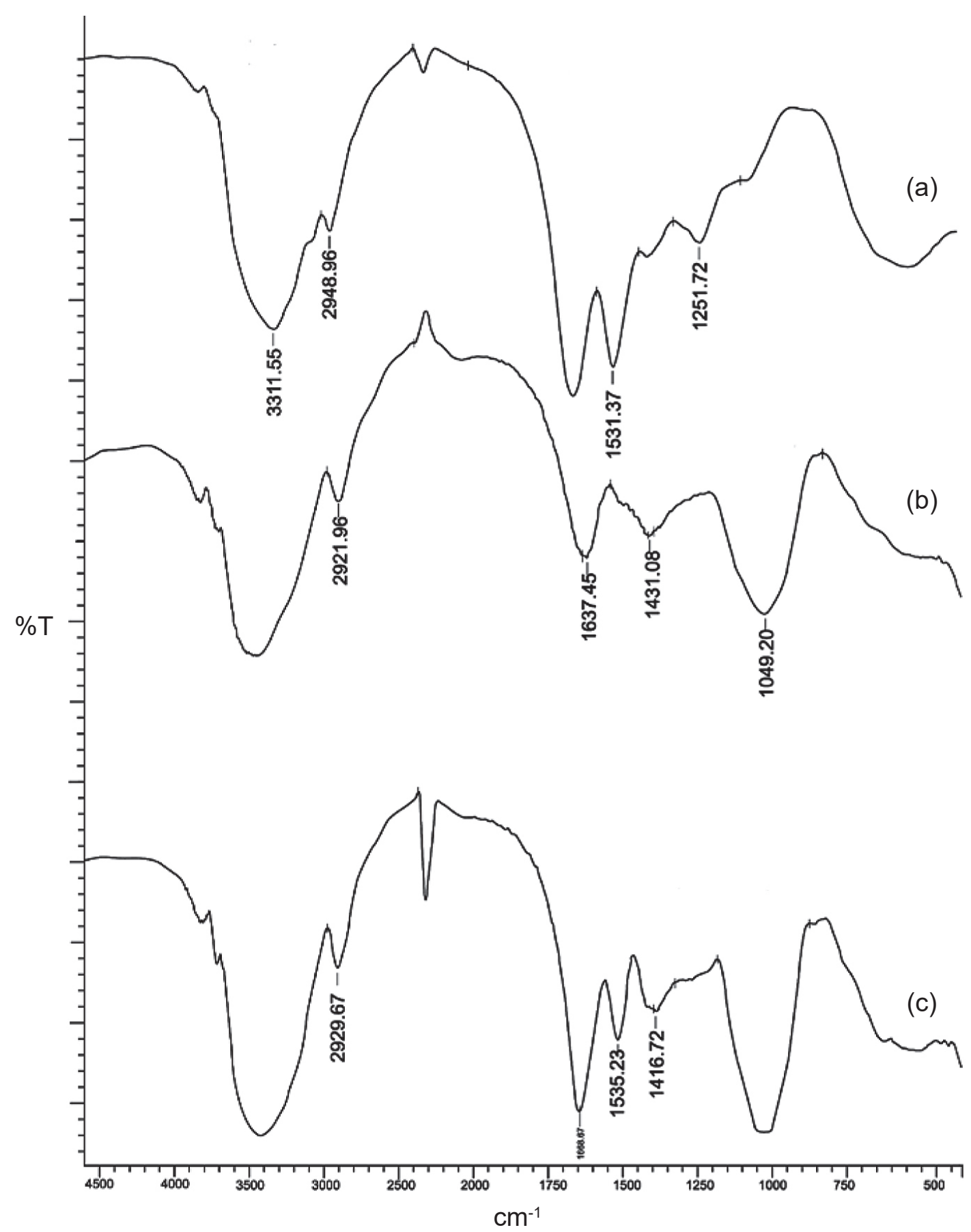

FIGURE 2. FT-IR spectra of (a) GA, (b) Lyz, and (c) Lyz-GA conjugate. Conjugated Lyz was prepared under optimum condition (pH 8.5 and Lyz-GA weight ratio of $1: 4$ incubated at $60^{\circ} \mathrm{C}$ for 10 days).

color intensity [Scaman et al., 2006]. As the incubation time increased, the intensity of the diffused bands increased proportionately such that the highest degree of conjugation was obtained after 10 days.

Also different mass ratios of Lyz to GA including 1:1, $1: 2$ and $1: 4$ were studied (data not shown, preliminary study). As a result, application of $\mathrm{pH} 8.5$, time incubation of 10 days and mass ratio of Lyz to GA 1:4 were utilized as the optimum conditions for the following experiments. In order to obtain pure Lyz-GA conjugate, a gel permeation chromatography was performed on a Sephadex G-100 column, fractions were collected, lyophilized and used for the following experiments.

\section{Fourier Transform Infrared Spectroscopy (FTIR)}

FTIR was applied in order to study the reaction between Lyz and GA. In Figure 2, FTIR spectra of Lyz and GA (as the controls) are shown to be compared with FTIR spectra of Lyz-GA conjugate. Figure 2a shows that GA has two strong bands at $1637 \mathrm{~cm}^{-1}$ and $1431 \mathrm{~cm}^{-1}$ which are due to asymmetric and symmetric stretching vibration of the carboxylic acid salt - $\mathrm{COO}^{-}$and peak at $1049 \mathrm{~cm}^{-1}$ is related to the stretching of the C-O bond [Nichols et al., 1985]. In Figure 2b, the FTIR spectrum of Lyz shows two main peaks at 1656 and $1533 \mathrm{~cm}^{-1}$ related to amide I and II, respectively. Two weak absorption bands at 3500 and $3400 \mathrm{~cm}^{-1}$ are respectively associated with asymmetrical and symmetrical N-H 
TABLE 1. Effect of conjugation with GA on the solubility of Lyz at different $\mathrm{pH}$ and temperatures .

\begin{tabular}{l|c|c|c|c|c|c|c}
\hline \multirow{2}{*}{ Samples } & \multicolumn{3}{|c|}{ Solubility (\%) at different $\mathrm{pH}$} & \multicolumn{3}{c}{ Solubility $(\%)$ at different temperatures $\left({ }^{\circ} \mathrm{C}\right)$} \\
\cline { 2 - 7 } & 3 & 5 & 7 & 9 & 25 & 40 & 60 \\
\hline Lyz & $98 \pm 0.6^{\mathrm{a}, \mathrm{A}}$ & $98 \pm 1.0^{\mathrm{a}, \mathrm{A}}$ & $97 \pm 1.1^{\mathrm{a}, \mathrm{A}}$ & $94 \pm 1.0^{\mathrm{b}, \mathrm{A}}$ & $99 \pm 1.3^{\mathrm{a}, \mathrm{A}}$ & $96 \pm 1.4^{\mathrm{b}, \mathrm{A}}$ & $90 \pm 0.9^{\mathrm{c}, \mathrm{A}}$ \\
Lyz $^{*}$ (control) & $82 \pm 1.2^{\mathrm{a}, \mathrm{B}}$ & $80 \pm 1.9^{\mathrm{a}, \mathrm{A}}$ & $73 \pm 2.6^{\mathrm{a}, \mathrm{C}}$ & $68 \pm 1.9^{\mathrm{a}, \mathrm{B}}$ & $83 \pm 2.7^{\mathrm{a}, \mathrm{B}}$ & $76 \pm 2.2^{\mathrm{b}, \mathrm{B}}$ & $62 \pm 2.6^{\mathrm{c}, \mathrm{C}}$ \\
${\text { Lyz}-G A^{* *}}$ & $97 \pm 2.4^{\mathrm{A}, \mathrm{C}, \mathrm{B}}$ & $87 \pm 1.9^{\mathrm{a}, \mathrm{b}, \mathrm{A}}$ & $81 \pm 0.5^{\mathrm{a}, \mathrm{B}}$ & $90 \pm 0.6^{\mathrm{b}, \mathrm{C}, \mathrm{A}}$ & $97 \pm 2.1^{\mathrm{a}, \mathrm{A}}$ & $94 \pm 2.0^{\mathrm{a}, \mathrm{A}}$ & $83 \pm 1.9^{\mathrm{b}, \mathrm{B}}$ \\
\hline
\end{tabular}

Results shown in the table represent mean values \pm SD of three replications. ${ }^{*}$ Lyz alone was heated under optimum condition (pH 8.5 , incubated at $60^{\circ} \mathrm{C}$ for 10 days). ${ }^{*}$ Conjugated Lyz was prepared under optimum condition ( $\mathrm{pH} 8.5$ and Lyz-GA weight ratio of 1:4 incubated at $60{ }^{\circ} \mathrm{C}$ for 10 days). ${ }^{8}$ In each column different superscript letters indicate significant difference $(\mathrm{p}<0.05)$. In each row different superscript uppercase letters indicate significant difference $(\mathrm{p}<0.05)$.

TABLE 2. Effect of conjugation with GA on the functional properties of Lyz.

\begin{tabular}{l|c|c|c|c|c}
\hline Samples & EA $\left(\mathrm{A}_{500 \mathrm{~nm}}\right)$ & ES $(\mathrm{min})$ & $\% \mathrm{FC}(\mathrm{mL})$ & $\% \mathrm{FS}(\mathrm{min})$ & $\%$ DPPH (Radical Scavenging Activity) \\
\hline Lyz & $0.05 \pm 0.6^{\mathrm{c}}$ & $1.8 \pm 0.1^{\mathrm{c}}$ & $11.1 \pm 1.0^{\mathrm{c}}$ & $41.2 \pm 1.5^{\mathrm{c}}$ & $2.4 \pm 1.0^{\mathrm{c}}$ \\
Lyz $^{*}($ control $)$ & $0.06 \pm 0.009^{\mathrm{c}}$ & $2.2 \pm 0.5^{\mathrm{c}}$ & $15.1 \pm 0.96^{\mathrm{b}}$ & $59.1 \pm 2.5^{\mathrm{b}}$ & ND \\
Lyz-GA** $^{*}$ & $0.9 \pm 0.007^{\mathrm{a}}$ & $6.5 \pm 0.1^{\mathrm{a}}$ & $82.3 \pm 1.8^{\mathrm{a}}$ & $86.2 \pm 1.2^{\mathrm{a}}$ & $25.1 \pm 1.5^{\mathrm{a}}$ \\
GA & $0.18 \pm 0.05^{\mathrm{b}}$ & $3.4 \pm 0.1^{\mathrm{b}}$ & $0^{\mathrm{d}}$ & $12.1 \pm 0.9^{\mathrm{b}}$ & $2.0 \pm 0.1^{\mathrm{c}}$ \\
\hline
\end{tabular}

Results shown in the table represent mean values $\pm \mathrm{SD}$ of three replications. ${ }^{*}$ Lyz alone is heated under optimum condition $\left(\mathrm{pH} 8.5\right.$, incubated at $60{ }^{\circ} \mathrm{C}$ for 10 days). ${ }^{* *}$ Conjugated Lyz is prepared under optimum condition ( $\mathrm{pH} 8.5$ and Lyz-GA weight ratio of $1: 4$ incubated at $60{ }^{\circ} \mathrm{C}$ for 10 days). ${ }^{8}$ In each column different superscript letters indicate significant difference $(p<0.05)$. ND: Not determined.

stretching. Finally, in Lyz-GA conjugate (Figure 2 c), due to the reaction between amino group of Lyz and carbonyl group of GA, carbonyl-amide region changes significantly. The $-\mathrm{NH}_{3}^{+}$ group (band at $1533 \mathrm{~cm}^{-1}$ ) and asymmetric and symmetric -CHO stretching vibration (at $1637 \mathrm{~cm}^{-1}$ and $1431 \mathrm{~cm}^{-1}$ ) disappeared or moved to $1535 \mathrm{~cm}^{-1}$ and 1413 for amine and carbonyl groups, respectively. The appearance of those new bands confirms the formation of Schiff base $(\mathrm{C}=\mathrm{N})$ between the carbonyl group of GA and the amino group of Lyz as a result of Maillard reaction. Interestingly, the results given by this experiment are in great agreement with Espinosa-Andrews et al. [2010] who showed the interaction of the functional groups of GA and chitosan by using FTIR.

\section{Functional properties}

\section{Solubility of Lyz-GA conjugates}

It has already been presented that some proteins have different solution properties under different heat treatment temperature and $\mathrm{pH}$ [deWit \& Klarenbeek, 1984]. Therefore, the effect of $\mathrm{pH}$ and temperature on the solubility of Lyz-GA conjugates was studied. As reported in Table 1, although Lyz alone has a great solubility in all pHs, studied in this work, compared to Lyz-GA conjugates showing a decrease in their solubility with a maximum solubility at $\mathrm{pH}$ 3.0. Considering solubility of heated Lyz, the conjugates showed a significantly $(\mathrm{p}<0.05)$ increased solubility at the whole studied $\mathrm{pH}$ range. These observations suggest that conjugation with GA has a protective effect against heat-induced denaturation and aggregation of Lyz molecules. Additionally, the covalent attachment of GA to Lyz improves the hydrophilicity of the Lyz, consequently increasing the solubility [Hashemi et al., 2014].
In an attempt to study the effect of different temperature on Lyz solubility, the samples were incubated at different temperatures at $\mathrm{pH} 3.0$ (optimum $\mathrm{pH}$ ). As shown in Table 2, however increasing the temperature from 25 to $60^{\circ} \mathrm{C}$ decreased the solubility of all samples, solubility of Lyz-GA conjugate was improved compared to the control. It is believed that the presence of large hydrophilic molecules, such as GA, prevents aggregation and precipitation of protein molecules, thereby increasing their stability and solubility [Babiker, 2002].

\section{Emulsifying properties}

Owing to the fact that the application of protein-polysaccharide complexes to stabilize the emulsions is of paramount interest [Evans et al., 2013], EA and ES of the conjugates were studied. Table 2 shows that the emulsifying properties of the Lyz-GA conjugates were significantly $(p<0.05)$ enhanced compared to these of the native or heated Lyz. For example, EA of the conjugate was about 18 times that of native Lyz. ES of the emulsion turbidity for the conjugate was more than 6 min, whereas ES of Lyz was less than 2 min. The role of Lyz in stabilization of emulsion is related to the anchorage of the hydrophobic residues of Lyz molecule to the surface of the oil droplet during emulsion formation. Moreover, the orientation of the hydrophilic moiety of GA to the aqueous layer of emulsion accelerates the formation of the thick steric stabilizing layer around the emulsion and prevents the coalescence of the oil droplets. Thus, EA and ES improvement is conducted by contribution of both macromolecules of protein (Lyz) and polysaccharide (GA) through interaction with oil and water phases of emulsion [Song et al., 2002; Flanagan \& Singh, 2006; Jiménez-Castaño et al., 2007; Diftis \& Kiosseoglou, 2003; Garti \& Leser, 2001]. 


\section{Foaming properties}

Foam formation by air bubbles highly affects the texture and the rheological properties of foods [Sadahira et al., 2016]. As summarized in Table 2, significant $(p<0.05)$ improvement is achieved in FC and FS by conjugation. For example, conjugation enhanced FS in Lyz alone from $41 \mathrm{~min}$ to 86 min in Lyz-GA conjugate. It is concluded that covalent attachment of polysaccharide to protein can improve the FS by forming a viscoelastic layer around the bubbles. Also, the higher FC occurs through increasing the surface tension of the bubbles [Schmitt et al., 2005].

\section{Heat stability}

As observed in Figure 3, native and heated Lyz started experiencing high turbidity at temperature over $60^{\circ} \mathrm{C}$, while Lyz-GA conjugates started slightly increase in turbidity above $70^{\circ} \mathrm{C}$. This observation suggests that the covalent attachment of GA to Lyz forms a heat-resistant protein because of GA protecting role as a molecular guardian against aggregation of unfolded proteins.

\section{DPPH radical scavenging activity}

The relatively stable DPPH radical has been mostly used to evaluate the ability of compounds to act as free radical scavengers or hydrogen donors and thus to indicate antioxidant activity [Morales \& Jiménez-Pérez, 2001]. The results (Table 2) show that there was a significant $(\mathrm{p}<0.05)$ increase in the scavenging activity of Lyz-GA conjugate towards DPPH radical, whereas none of Lyz and GA alone presented significant scavenging activity. It is suggested that browning reactions, like the Maillard reaction, form products with an improved antioxidant activity [Nakamura et al., 1991; Morales \& Jiménez-Pérez, 2001].

\section{Antimicrobial activity of Lyz}

The result of antibacterial activity of Lyz derivatives is presented in Figure 4. It is obviously shown that Lyz bactericidal activity against $E$. coli and $S$. aureus at $37^{\circ} \mathrm{C}$ increases with enzyme concentration. The antimicrobial activity of the Lyz-GA conju-

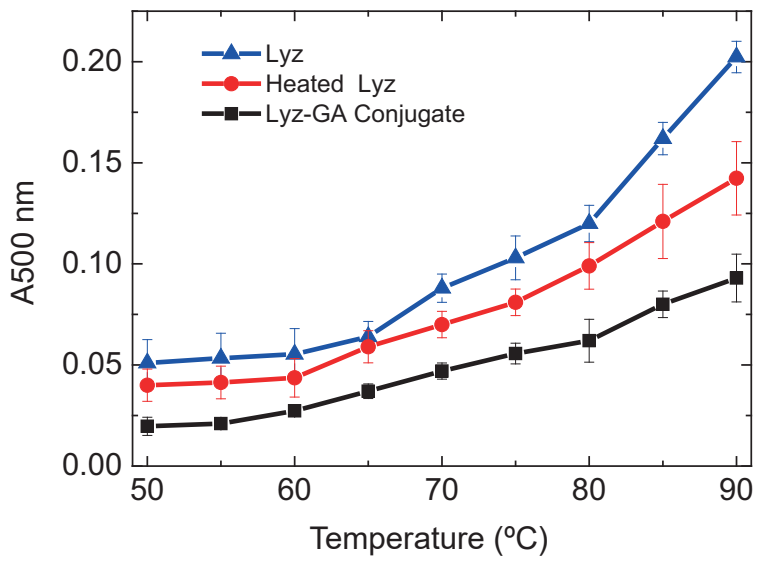

FIGURE 3. Heat stability of Lyz and Lyz-GA conjugate. Conjugated Lyz was prepared under optimum condition ( $\mathrm{pH} 8.5$ and Lyz-GA weight ratio of $1: 4$ incubated at $60^{\circ} \mathrm{C}$ for 10 days). Each point is the average of three replicates. gate was significantly $(\mathrm{p}<0.05)$ higher than Lyz alone or heated Lyz, such that at $0.27 \mu \mathrm{mol} / \mathrm{L}$ a decrease of about 3 and $2.5 \mathrm{log}$ of $E$. coli and $S$. aures number was observed, respectively.

A long-held belief is that Lyz has antimicrobial effects on Gram-positive bacteria [Aminlari et al., 2014] and attacks only certain positions of glycosidic bonds between $\mathrm{N}$-acetylhexosamines of the peptidoglycan layer in bacterial cell walls. Cooperating factors such as using detergents and heat treatments destabilize and, consequently, solubilize the LPS of the outer membranes of Gram-negative bacteria. For instance, 1\% SDS solubilizes the purified outer membrane isolated from $E$. coli $K$-12 without any sediment [Nakamura et al., 1991]. However,

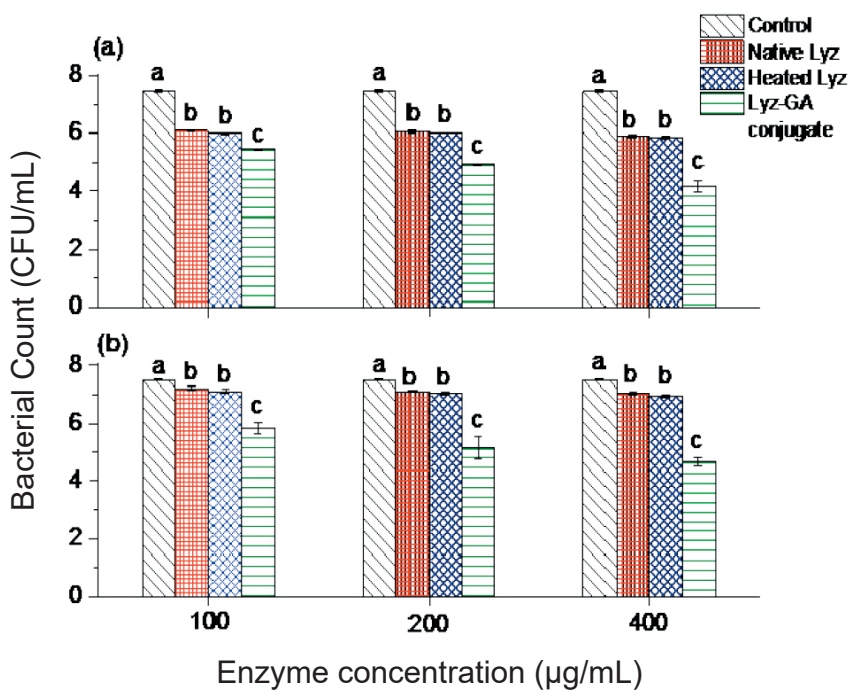

FIGURE 4. Antimicrobial activity of Lyz derivatives against (a) E. coli, and (b) $S$. aureus. The enzyme bacterial suspensions were incubated at $37^{\circ} \mathrm{C}$ for $16 \mathrm{~h}$. Each point is the average of three replicates. Columns with different letters are significantly different $(\mathrm{p}<0.05)$. Control (no treatment) (columns filled with black lines), Native Lyz (columns filled with red lines), Lyz heated at $\mathrm{pH} 8.5$ for 10 days (columns filled with blue lines), Lyz heated at $60^{\circ} \mathrm{C}$ and $\mathrm{pH} 8.5$ for 10 days in a Lyz:GA weight ratio of 1:4 (columns filled with green lines). Columns with different letters are significantly different $(\mathrm{p}<0.05)$. In all cases the data for $0.27 \mu \mathrm{mol} / \mathrm{L}$ is significantly different from other concentrations.

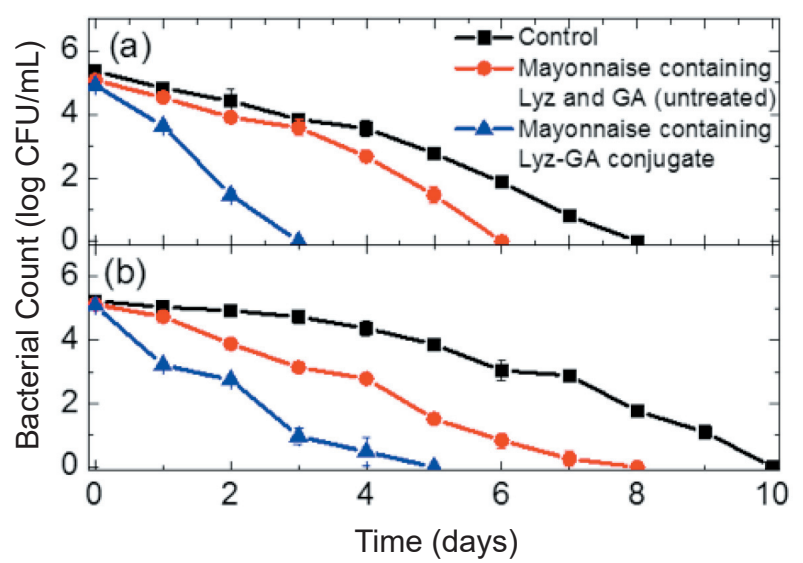

FIGURE 5. Antibacterial activity of Lyz-GA conjugate in contaminated mayonnaise with (a) E. coli, and (b) S. aureus. Each point is the average of three replicates. 
TABLE 3. Stability loss and pH measurement during storage time for control samples, mayonnaise containing Lyz and GA (untreated) and mayonnaise containing Lyz-GA conjugate.

\begin{tabular}{l|c|c|c|c|c|c}
\hline \multirow{2}{*}{$\begin{array}{l}\text { Storage } \\
\text { time (days) }\end{array}$} & \multicolumn{3}{|c|}{ Stability loss $(w / w)$} & \multicolumn{2}{c}{$\mathrm{pH}$} \\
\cline { 2 - 7 } & Control* $^{*}$ & $\begin{array}{c}\text { Lyz and GA** } \\
\text { (untreated) }\end{array}$ & $\begin{array}{c}\text { Lyz-GA } \\
\text { Conjugate }\end{array}$ & Control & $\begin{array}{c}\text { Lyz and GA } \\
\text { (untreated) }\end{array}$ & $\begin{array}{c}\text { Lyz-GA } \\
\text { Conjugate }\end{array}$ \\
\hline 3 & $2.9 \pm 0.54^{\mathrm{aD}}$ & $2.1 \pm 0.77^{\mathrm{abC}}$ & $1.6 \pm 0.50^{\mathrm{bC}}$ & $3.92 \pm 0.021^{\mathrm{aAB}}$ & $3.88 \pm 0.015^{\mathrm{aABC}}$ & $3.92 \pm 0.030^{\mathrm{aA}}$ \\
8 & $6.3 \pm 1.1^{\mathrm{aC}}$ & $4.4 \pm 0.83^{\mathrm{bC}}$ & $7.2 \pm 0.68^{\mathrm{bC}}$ & $3.88 \pm 0.010^{\mathrm{aCD}}$ & $3.85 \pm 0.020^{\mathrm{bDE}}$ & $3.90 \pm 0.010^{\mathrm{aABC}}$ \\
10 & $18 \pm 1.2^{\mathrm{aB}}$ & $15.2 \pm 1.5^{\mathrm{abB}}$ & $7.11 \pm 1.3^{\mathrm{bB}}$ & $3.86 \pm 0.028^{\mathrm{aCD}}$ & $3.85 \pm 0.011^{\mathrm{aDE}}$ & $3.89 \pm 0.010^{\mathrm{aABC}}$ \\
15 & $26.4 \pm 1.3^{\mathrm{aA}}$ & $22.9 \pm 1.4^{\mathrm{abA}}$ & $2.19 \pm 1.6^{\mathrm{bA}}$ & $3.87 \pm 0.010^{\mathrm{aD}}$ & $3.85 \pm 0.005^{\mathrm{aE}}$ & $3.86 \pm 0.015^{\mathrm{aC}}$ \\
\hline
\end{tabular}

Results shown in the table represent mean values \pm SD of three replications. *Control sample contains mayonnaise without any Lyz or GA. *** Mayonnaise containing Lyz and GA without Maillard reaction. ${ }^{8}$ In each column different superscript letters indicate significant difference $(\mathrm{p}<0.05)$. In each row different superscript uppercase letters indicate significant difference $(\mathrm{p}<0.05)$.

added detergents or some surface-active compounds (such as SDS) are not necessarily desirable for the food industry. On the other hand, it has been reported that various hybrid proteins with polysaccharide (such as dextran or galactomannan) exhibit excellent functional properties [Nakamura et al., 1991; Aminlari et al., 2005]. Therefore, in order to improve the surface properties of the protein, conjugation with a polysaccharide is desired for industrial applications. In addition, these compounds are capable of solubilizing the outer membranes of Gram-negative bacteria [Nakamura et al., 1991]. An excellent surface activity of Lyz-GA conjugate could result in destruction of the outer membrane of the Gram-negative bacterial cells.

In order to investigate whether Lyz-GA conjugates keep the antibacterial activity in food systems, the best concentration $(0.27 \mu \mathrm{mol} / \mathrm{L})$ obtained by the previous test was applied in mayonnaise. As shown in Figure 5a, E. coli $K$-12 growth was inhibited in the mayonnaise containing Lyz-GA conjugate after only 3 days, while in mayonnaise including Lyz and GA (untreated) as well as the control, growth inhibition occurred after 6 and 8 days, respectively. Figure 5b also shows that $S$. aures growth in the mayonnaise containing Lyz-GA conjugate was inhibited within 5 days, while the growth was still present in the mayonnaise including Lyz and GA (untreated) and control until the fifth day, instead their population was inhibited after 8 and 10 days, respectively. Thus, the presence of the conjugate in mayonnaise expedites the death rate of both $S$. aureus and $E$. coli $K-12$, which is in agreement with the fact that antibacterial properties of Lyz-GA conjugate work not only in experimental culture, but also in food systems. A similar result on cheese including Lyz-dextran conjugate has been previously observed by Amiri et al. [2008].

\section{Emulsion stability of mayonnaise including Lyz-GA conjugate}

The results from storing three kinds of mayonnaise within 15 days show that the presence of Lyz-GA conjugate led to a decrease in syneresis and in water separation delay (Table 3 ). Therefore, applying conjugate in mayonnaise is an appropriate proof for great emulsification properties of the conjugate. In fact, the presence of Lyz as a protein moiety and GA as a carbohydrate moiety in the conjugate results in the formation of a protein-polysaccharide network, which links the wa- ter droplets in mayonnaise and, subsequently, prevents water releasing or syneresis. Hence, it is highly possible to keep the emulsion of mayonnaise in a more stable position [Mandala et al., 2004]. Furthermore, results of $\mathrm{pH}$ measurement of mayonnaise presented in Table 3 show that adding Lyz-GA conjugate to the mayonnaise does not change the $\mathrm{pH}$ significantly compared to the control mayonnaise, and the standard range of $\mathrm{pH}$ (3.8-4.1) in mayonnaise is still preserved. Since mayonnaise is considered as a cold emulsified sauce, keeping the $\mathrm{pH}$ in the standard range is of paramount importance to avoid sensitivity to spoilage [Fialová et al., 2008; Xiong et al., 2000].

\section{Rheological experiments}

\section{Linear viscoelastic response}

Due to the fact that protein and polysaccharides remarkably affect the structural and textural properties of foods, the rheological experiments on the mayonnaise including Lyz-GA conjugates were performed. Figure 6 depicts results of the dynamic frequency sweep (DFS) experiments performed in a linear viscoelastic regime for different mayonnaise samples. For all the samples elastic modulus ( $\left.G^{\prime}\right)$ was greater

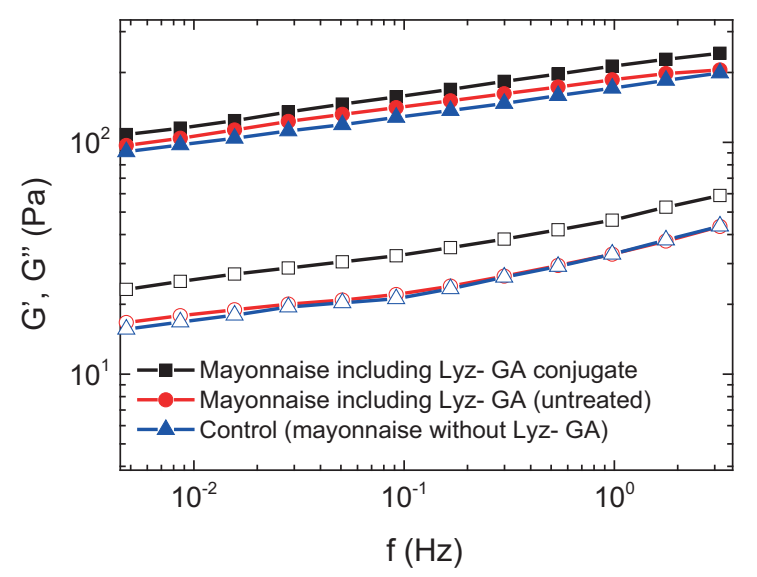

FIGURE 6. Storage modulus ( $\mathrm{G}^{\prime}$, solid symbols) and loss modulus ( $\mathrm{G}^{\prime \prime}$, open symbols) as a function of frequency, $f$, in the linear viscoelastic regime for mayonnaise containing Lyz- GA conjugate, Lyz and GA (untreated) and control (without Lyz and GA) as indicated. 
than the loss modulus (G'), (G'>G') in the whole frequency windows, which is indicative of the solid-like response. Both G' and G" showed a slow increase with frequency, which was in agreement with findings reported by Mun et al. [2009] and Laca et al. [2010]. This gel-like response is due to the formation of the network of oil droplets through depletion interactions [Mandala et al., 2004; Krstonošić et al., 2009; Liu et al., 2007]. This depletion-forcing aggregation is a result of the presence of unadsorbed gum molecules, which creates osmotic pressure and pushes the droplets leading to the formation of a strong network of droplets.

As reported by Laca et al. [2010], the higher elasticity (larger values of $G^{\prime}$ ) indicates the formation of more stable emulsions. Therefore, dynamic frequency sweep experiments can be used as a predictive tool to probe the emulsion stability. Using Lyz-GA conjugate increases the mayonnaise elasticity indicating that the conjugate highly improves the emulsion stability as mentioned in section 3.5, while Lyz and GA without treatment slightly increase the elasticity, but not as much as the Lyz-GA conjugate. However, it should be noted that adding Lyz and GA with and without treatment does not change the linear rheological response of mayonnaise significantly.

\section{Dynamic strain sweep (DSS) experiments}

Dynamic strain sweep (DSS) experiments are used to determine the limit of linear viscoelastic regime and also to study the yielding response of materials. In DSS experiment, a sinusoidal deformation at a constant frequency is applied on the material and the amplitude of the deformation is increased. At low strain amplitudes both G' and G" show constant values indicative of being in the linear viscoelastic regime. In this regime, the structure is not affected by the shear. With increasing the strain amplitude, G' decreases and shows the shoulder, while G" increases and shows a maximum indicative of entering the non-linear viscoelastic regime, more increase in the strain amplitude, results in a crossover between G' and G'. This crossover is considered as the yielding or melting point, since after that G' becomes greater than G'

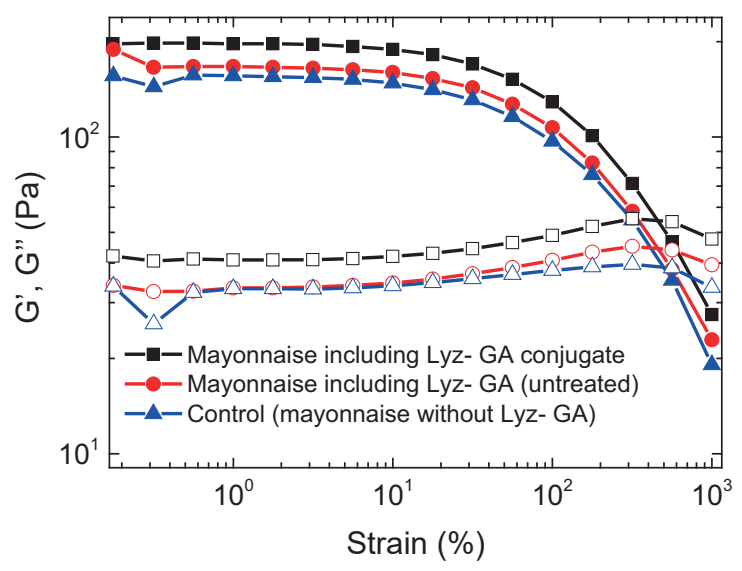

FIGURE 7. Storage modulus (G', solid symbols) and loss modulus $\left(\mathrm{G}^{\prime \prime}\right.$, open symbols) as a function of strain amplitude $\gamma_{0}$ at the frequency of $f=1 \mathrm{~Hz}$ for mayonnaise containing Lyz-GA conjugate, Lyz and GA (untreated) and control (without Lyz and GA) as indicated.
TABLE 4. Yield strain and yield stress values obtained from Figure 7.

\begin{tabular}{lcc}
\hline Sample & Yield strain $(\%)$ & Yield stress $(\mathrm{Pa})$ \\
\hline Lyz-GA conjugate & 458 & 352 \\
Lyz-GA** (untreated) $^{*}$ & 459 & 291 \\
Control* $^{*}$ & 498 & 275 \\
\hline
\end{tabular}

*Control sample contains mayonnaise without any Lyz or GA. ** Mayonnaise containing Lyz and GA without Maillard reaction.

while the material is a fluid. Figure 7 shows such DSS experiments performed at the frequency of $f=1 \mathrm{~Hz}$. All the samples show a typical expected DSS response with nearly the same limit of linear viscoelastic regime, which is below the strain amplitude of $10 \%$. Table 4 summarizes the values of yield strain and yield stress of mayonnaise including Lyz-GA conjugate, Lyz and GA (untreated) and control (without any Lyz or GA). As seen in Table 4, the control sample exhibits the largest yield strain while the lowest yield strain is for the mayonnaise containing conjugated Lyz-GA indicative of having more brittle structure. The intense of yield stress is related to the value of elastic modulus and yield strain $\left(\tau_{\mathrm{y}}=2 \mathrm{G} \gamma_{\mathrm{y}}\right.$, where $\mathrm{G}$ and $\gamma_{\mathrm{y}}$ are elastic modulus and yield strain, respectively). The control has the lowest yield stress, while the highest yield stress is for the mayonnaise containing conjugated Lyz-GA, in agreement with linear viscoelastic response. This result indicates that conjugated Lyz-GA is able to bear higher stresses without yielding and so is the most stable emulsion.

\section{Steady shear flow response}

Figure 8 shows the flow curve (steady state shear stress and shear viscosity versus shear rate) for the mayonnaise samples. For all the samples, viscosity was decreasing with increasing the shear rate, showing the shear-thinning behavior as expected [Pons et al., 1994; Juszczak et al., 2003; Worrasinchai et al., 2006; Goshawk \& Binding, 1998]. At high shear rates, the hydrodynamic forces deform the aggregates which eventually break them apart, resulting in the viscosity reduction [McClements, 1999]. However, at low shear rates droplets aggregate under particular shears leading to the formation of a three-dimensional network of aggregated droplets, because the depletion attractions are dominated over hydrodynamic forces. Shear stress at high shear rates shows a sub linear response, which is again indicative of shear-thinning behavior. However, as shown in DFS experiments (Figure 6), all the mayonnaise samples showed solid-like response. This means that the flow curve should show a stress plateau at low shear rates, being indicative of yield stress response expected for solid-like materials [Ballesta et al., 2013]. At low shear rates, however, this plateau is not observed and the stress keeps decreasing with a shoulder happening around shear rate of $10 \mathrm{~s}^{-1}$. The reason could be wall slip due to shear-enhanced aggregation at low rates similar to what is observed in the colloidal depletion gels [Ballesta et al., 2013] or shear-induced particle migration [Goshawk \& Binding, 1998]. One way to overcome the slip can be using serrated plates with the roughness higher than structural length-scale of the sample. Although, there is no sign of slip in the oscillatory ex- 


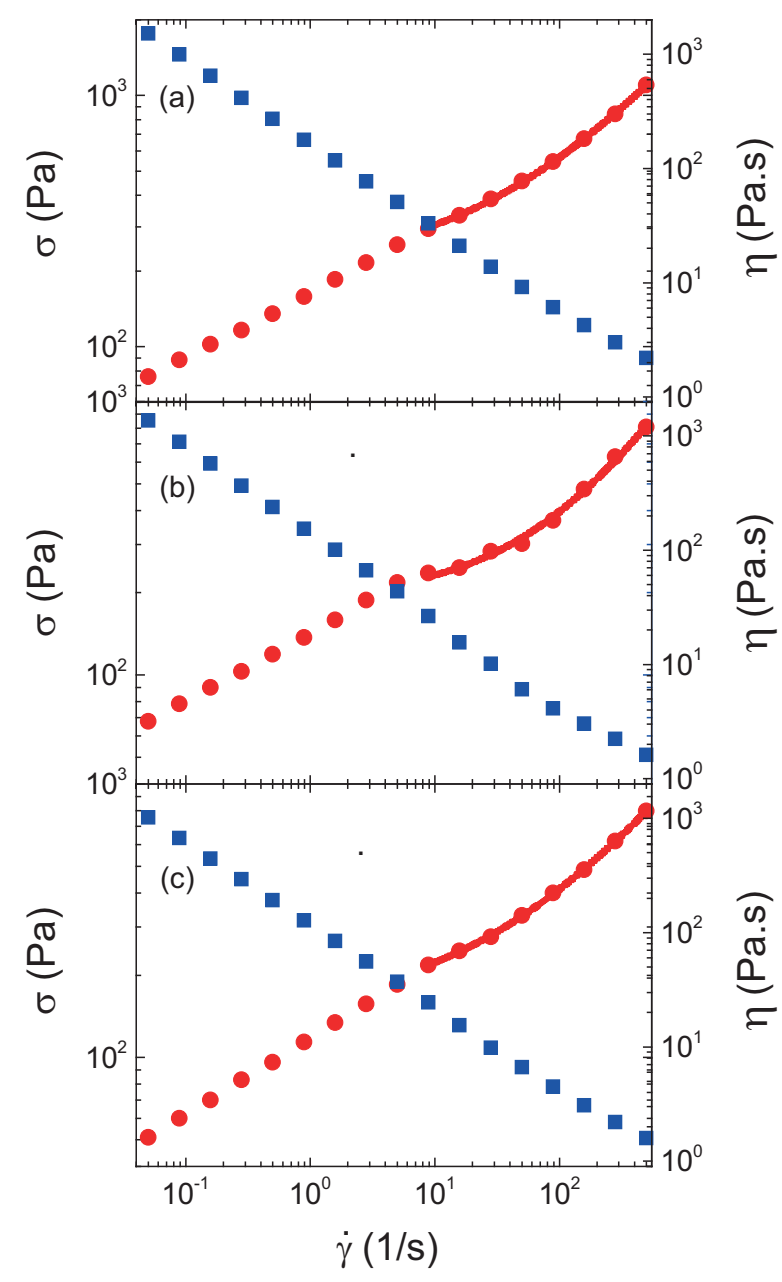

FIGURE 8. Shear stress $\sigma$ (red circles) and viscosity $\eta$ (blue squares) as a function of shear rate $\dot{\gamma}$ for: (a) mayonnaise containing Lyz-GA conjugate, (b) Lyz and GA (untreated), and (c) control (without Lyz and GA) The red curves in (a), (b), and (c) are the fitting of Herschel-Bulkley equation to the experimental data.

periments, which is in agreement with the results reported by Ma and Barbosa-Cánovas et al. [1995]. To avoid the effect of the slip on the fitting, the Herschel-Bulkley equation is fitted for the shear rates larger than $10 \mathrm{~s}^{-1}$ that are in the nonslipping part of the flow curve (Figure 8).

Mayonnaise containing conjugated Lyz-GA showed the highest and the control exhibited the lowest yield stress, which are in agreement with the findings in DSS experiments and also with linear viscoelastic results where mayonnaise with conjugated Lyz-GA showed the highest and the control exhibited the lowest elastic modulus. All the samples showed the flow behavior index (n) less than one, which is indicative of the shear-thinning response (Table 5).

\section{Sensory evaluation of mayonnaise including Lyz-GA conjugate}

Sensory evaluation scores of mayonnaise including Lyz-GA conjugate and commercial mayonnaise are shown in Figure 9. Although the color evaluation of conjugates (data not shown) showed a statistical difference $(\mathrm{p}<0.05)$ between the produced conjugate and Lyz alone, the sensory
TABLE 5. Yield stress and flow index behavior (n) values obtained from fitting of Herschel-Bulkley equation to data of Figure 8.

\begin{tabular}{lcc}
\hline Sample & Yield stress $(\mathrm{Pa})$ & $\mathrm{n}$ \\
\hline Lyz-GA conjugate & 206 & 0.478 \\
Lyz-GA** (untreated) & 189 & 0.475 \\
Control* $^{*}$ & 150 & 0.557 \\
\hline
\end{tabular}

*Control sample contains mayonnaise without any Lyz or GA. ** Mayonnaise containing Lyz and GA without Maillard reaction.

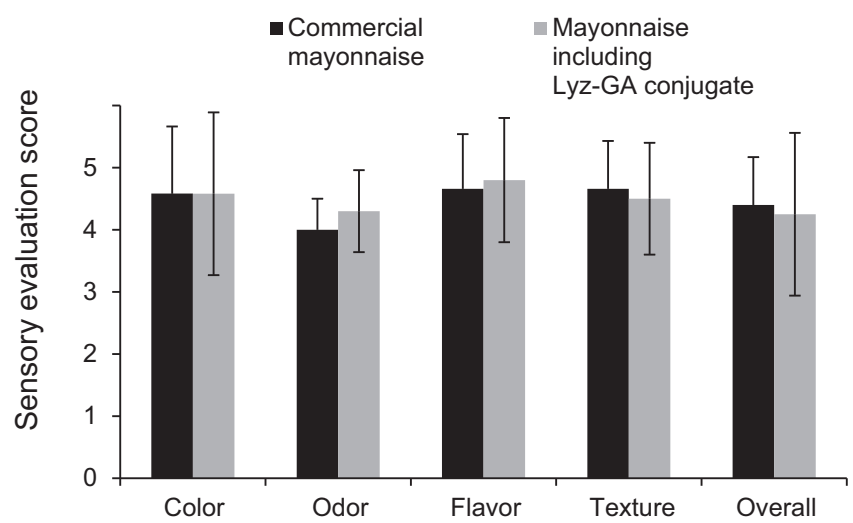

FIGURE 9. Sensory evaluation scores (color, odor, flavor, texture and overall) of commercial mayonnaise (empty columns) compared to the mayonnaise containing Lyz-GA conjugate (columns filled with black lines). Each point is the average of fifteen replicates performed by a sensory panel group.

panel did not distinguish a significant $(\mathrm{p}<0.05)$ difference between the appearance and color of mayonnaise containing the conjugate and the commercial mayonnaise. Generally, scores given to the two kinds of mayonnaise were not significantly $(\mathrm{p}<0.05)$ different, showing that the sensory properties of mayonnaise including Lyz-GA conjugate were as acceptable as those of the commercial mayonnaise.

\section{CONCLUSION}

In the present study, conjugation of Lyz with GA was performed in an effort to create a multifunctional product applicable in sectors of the food industry, such as mayonnaise production. We clearly demonstrate that the production of Lyz-GA conjugate is performed efficiently by controlling the Maillard reaction conditions consisting of $\mathrm{pH}$, reaction time and weight ratio of protein to polysaccharide. Therefore, the optimum condition to produce the conjugate is determined and the product exhibits excellent functional properties and improves antibacterial spectrum in so far as the mentioned properties, such as antimicrobial and emulsifying properties, are kept in mayonnaise. Moreover, the application of the conjugate in mayonnaise does not disturb the acceptability of the rheological and sensorial evaluation of mayonnaise. In conclusion, this study confirms that the Lyz-GA conjugate can be a suitable candidate as a natural preservative and emulsifier with improved functional properties in different food systems or drug formulation. 


\section{RESEARCH FUNDING}

This research was financially supported by grant number 80-AG-1361-C 117 from Shiraz University Research Council.

\section{CONFLICT OF INTERESTS}

Authors declare no conflict of interests.

\section{REFERENCES}

1. Aminlari L., Hashemi M.M., Aminlari M., Modified lysozymes as novel broad spectrum natural antimicrobial agents in foods. J. Food Sci., 2014, 79, R1077-1090.

2. Aminlari M., Ramezani R., Jadidi F., Effect of Maillard-based conjugation with dextran on the functional properties of lysozyme and casein. J. Sci. Food Agr., 2005, 85, 2617-2624.

3. Amiri S., Ramezani R., Aminlari M., Antibacterial activity of dextran-conjugated lysozyme against Escherichia coli and Staphylococcus aureus in cheese curd. J. Food Prot., 2008, 71, 411-415.

4. Arabshahi-D S., Devi D.V., Urooj A., Evaluation of antioxidant activity of some plant extracts and their heat, $\mathrm{pH}$ and storage stability. Food Chem., 2007, 100, 1100-1105.

5. Babiker E.E., Effect of chitosan conjugation on the functional properties and bactericidal activity of gluten peptides. Food Chem., 2002, 79, 3, 367-372.

6. Ballesta P., Koumakis N., Besseling R., Poon W.C., Petekidis G., Slip of gels in colloid-polymer mixtures under shear. Soft Matter, 2013, 9, 12, 3237-3245.

7. Benucci I., Cappannella E., Liburdi K., Esti M., Inhibitory effect of ethanol, sulphur dioxide and proanthocyanidinic tannins on lysozyme antimicrobial activity in model wine. LWT - Food Sci Technol., 2016, 73, 320-325.

8. Chevalier F., Chobert J. M., Popineau Y., Georgette M., Haertle N., Haertle T., Improvement of functional properties of $\beta$-lactoglobulin glycated through the Maillard reaction is related to the nature of the sugar. Int. Dairy J., 2001, 11, 145-152.

9. deWit J.N., Klarenbeek G., Effects of various heat treatments on structure and solubility of whey proteins. J. Dairy Sci., 1984, 67, 11, 2701-2710.

10. Dickinson E., Hydrocolloids at interfaces and the influence on the properties of dispersed systems. Food Hydrocoll., 2003, 17, 1, 25-39.

11. Diftis N., Kiosseoglou V., Improvement of emulsifying properties of soybean protein isolate by conjugation with carboxymethyl cellulose. Food Chem., 2003, 81, 1, 1-6.

12. Espinosa-Andrews H., Sandoval-Castilla O., Vazquez-Torres H., Jaime Vernon-Carter E., Lobato-Calleros C., Determination of the gum Arabic-chitosan interactions by Fourier Transform Infrared Spectroscopy and characterization of the microstructure and rheological features of their coacervates. Carbohydr. Polym., 2010, 79, 3, 541-546.

13. Evans M., Ratcliffe I., Williams P.A., Emulsion stabilisation using polysaccharide-protein complexes. Curr. Opin. Colloid., 2013, 18, 4, 272-282.

14. Fialová J., Chumchalová J., Miková K., Hrůšová I., Effect of food preservatives on the growth of spoilage lactobacilli isolated from mayonnaise-based sauces. Food Contr., 2008, 19, 7, 706-713.
15. Flanagan J., Singh H., Conjugation of sodium caseinate and gum arabic catalyzed by transglutaminase. J. Agric. Food. Chem., 2006, 54, 19, 7305-7310.

16. Garti N., Leser M.E., Emulsification properties of hydrocolloids. Polymer. Adv. Tech., 2001, 12, 1-2, 123-135.

17. Goshawk J., Binding D., Rheological phenomena occurring during the shearing flow of mayonnaise. J. Rheol., 1998, 42, 1537-1553.

18. Hashemi M.M., Aminlari M., Moosavinasab M., Preparation of and studies on the functional properties and bactericidal activity of the lysozyme-xanthan gum conjugate. LWT - Food Sci Technol., 2014, 57, 2, 594-602.

19. Jiménez-Castaño L., Villamiel M., López-Fandiño R., Glycosylation of individual whey proteins by Maillard reaction using dextran of different molecular mass. Food Hydrocoll., 2007, 21, 3, 433-443.

20. Juszczak L., Fortuna T., Kośla A., Sensory and rheological properties of Polish commercial mayonnaise. Food/Nahrung, 2003, 47, 4, 232-235.

21. Kotlar C.E., Ponce A.G., Roura S.I., Improvement of functional and antimicrobial properties of brewery byproduct hydrolysed enzymatically. LWT - Food Sci Technol., 2013, 50, 2, 378-385.

22. Krstonošić V., Dokić L., Dokić P., Dapčević T., Effects of xanthan gum on physicochemical properties and stability of corn oil-in-water emulsions stabilized by polyoxyethylene (20) sorbitan monooleate. Food Hydrocoll., 2009, 23, 8, 2212-2218.

23. Laca A., Sáenz M.C., Paredes B., Díaz M., Rheological properties, stability and sensory evaluation of low-cholesterol mayonnaises prepared using egg yolk granules as emulsifying agent. J. Food Eng., 2010, 97, 2, 243-252.

24. Laemmli U.K., Cleavage of structural proteins during the assembly of the head of bacteriophage. T4. Nature, 1970, 227, 680-685.

25. Leuschner R.G., Boughtflower M.P., Standardized laboratoryscale preparation of mayonnaise containing low levels of it Salmonella enterica serovar Enteritidis. J. Food Protect., 2001, 64, 623-629.

26. Liu H., Xu X.M., Guo S.D., Rheological, texture and sensory properties of low-fat mayonnaise with different fat mimetics. LWT - Food Sci Technol., 2007, 40, 6, 946-954.

27. Ma L., Barbosa-Cánovas G.V., Rheological characterization of mayonnaise. Part II: Flow and viscoelastic properties at different oil and xanthan gum concentrations. J. Food Eng., 1995, 25, 409-425.

28. Mandala I.G., Savvas T.P., Kostaropoulos A.E., Xanthan and locust bean gum influence on the rheology and structure of a white model-sauce. J. Food Eng., 2004, 64, 3, 335-342.

29. McClements D.J., Food emulsions, principles, practice and technique. 1999, CRC Press Inc., Boca Raton, Florida, pp. 411-415.

30. Miralles B., Martínez-Rodríguez A., Santiago A., van de Lagemaat J., Heras A., The occurrence of a Maillard-type proteinpolysaccharide reaction between $\beta$-lactoglobulin and chitosan. Food Chem., 2007, 100, 3, 1071-1075.

31. Morales F.J., Jiménez-Pérez S., Free radical scavenging capacity of Maillard reaction products as related to colour and fluorescence. Food Chem., 2001, 72, 1, 119-125.

32. Mu L., Zhao H., Zhao M., Cui C., Liu L., Physicochemical properties of soy protein isolates-acacia gum conjugates. Czech J. Food Sci., 2011, 29, 2, 129-136.

33. Mun S., Kim Y.L., Kang C.G., Park K.H., Shim J.Y., Kim, Y.R., Development of reduced-fat mayonnaise using $4 \alpha$ GTase- 
-modified rice starch and xanthan gum. Int. J. Biol. Macromol., 2009, 44, 5, 400-407.

34. Nakamura S., Kato A., Kobayashi K., New antimicrobial characteristics of lysozyme-dextran conjugate. J. Agric. Food. Chem., 1991, 39, 4, 647-650.

35. Nichols P.D., Henson M.J., Guckert J.B., Nivens D.E., White D.C., Fourier transform-infrared spectroscopic methods for microbial ecology: analysis of bacteria, bacteri-polymer mixtures and biofilms. J. Microbiol. Methods., 1985, 4, 2, 79-94.

36. Phillips G.O., Williams P.A., Handbook of Hydrocolloids (1st ed.). 2000, Woodhead Publishing Limited, Cambridge, UK, pp. 252-270.

37. Pons M., Galotto M. J., Subirats S., Comparison of the steady rheological characterization of normal and light mayonnaises. Food Hydrocoll., 1994, 8, 3-4, 389-400.

38. Sadahira M.S., Rodrigues M.I., Akhtar M., Murray B.S., Netto F.M., Effect of egg white protein-pectin electrostatic interactions in a high sugar content system on foaming and foam rheological properties. Food Hydrocoll., 2016, 58, 1-10.
39. Scaman C., Nakai S., Aminlari M., Effect of pH, temperature and sodium bisulfite or cysteine on the level of Maillard-based conjugation of lysozyme with dextran, galactomannan and mannan. Food Chem., 2006, 99, 2, 368-380.

40. Schmitt C., Bovay C., Frossard P., Kinetics of formation and functional properties of conjugates prepared by dry-state incubation of $\beta$-lactoglobulin/acacia gum electrostatic complexes. J. Agric. Food. Chem., 2005, 53, 23, 9089-9099.

41. Song Y., Babiker E.E., Usui M., Saito A., Kato A., Emulsifying properties and bactericidal action of chitosan-lysozyme conjugates. Food Res. Int., 2002, 35, 5, 459-466.

42. Worrasinchai S., Suphantharika M., Pinjai S., Jamnong P., $\beta$-Glucan prepared from spent brewer's yeast as a fat replacer in mayonnaise. Food Hydrocoll., 2006, 20, 1, 68-78.

43. Xiong R., Xie G., Edmondson A.S., Modelling the $\mathrm{pH}$ of mayonnaise by the ratio of egg to vinegar. Food Contr., 2000, 11, 1, 49-56.

Submitted: 27 September 2016. Revised: 14 December 2016. Accepted: 25 January 2017. Published on-line: 17 May 2017. 
